\title{
Design, Construction and Evaluation of a Dual Operation Seed and Fertilizer Broadcaster for Farmers
}

\author{
Mele, E.F. $\quad$ Ndomi, B.M. $\quad$ Diraso, D.K. $\quad$ Dauda, M. Bulama, K.H. John. A.C. \\ School of Technology and Science Education, Modibbo Adama University of Technology Yola, Adamawa \\ State, Nigeria
}

\begin{abstract}
This paper presents a report on the design, construction and evaluation of a dual operation seed and fertilizer broadcasting device, an appropriate agricultural technology especially, for small scale peasant farmers in both rural and urban areas. It is an appropriate technology because its features eliminate the short coming on both traditional and existing physical devices being used for seed and fertilizer broadcasting. Relevant literature was reviewed. Engineering design was adopted in this study. Preliminary investigation was carried out to reliably and objectively establish the need for the new product. In carrying out the preliminary investigation, thirty (30) open ended and semi structured questionnaire were used to sample thirty end users' opinions on existing seed and fertilizer broadcasting devices. Percentage was used for analysis of data. The area of study for the preliminary investigation and the final study was Adamawa and Gombe States of Nigeria. The preliminary investigation revealed that farmers are dissatisfied with the high cost of the tractor mounted fertilizer broadcaster and they also expressed dissatisfaction with the traditional method since it is slow, energy consuming and has high health hazards. For this, respondents expressed a need for a device that is potable, has low energy requirement and is relatively cheap. After establishing the need for the new device, design specification, design criteria, production and assembly drawings were made. Materials selection was based on the design calculation made. The evaluation result revealed that the new product carried out the function for which it was designed. It was therefore recommended to entrepreneurs for mass production and for use by peasant farmers.
\end{abstract}

Keywords: Design, Construction, Evaluation, Fertilizer, Broadcasting.

DOI: $10.7176 /$ IEL/11-3-02

Publication date:October $31^{\text {st }} 2021$

\subsection{Introduction}

Every identified practical human need requires the services of physical tools that could be hand operated or externally powered. It is common knowledge that before a functional and efficient tool is produced; it must first pass through processes of design, construction and evaluation. In this regard, Garratt (1998) and Mele (2006) defined design as formation of plans for the satisfaction of human practical need (s). In the same vein, Apagu, Mele, Dobulo and Angulu (2010) defined tool or machine design as the art of planning or devising a new or an improved machine tool to accomplish specific practical function (s). On the other hand, construction, according to Garratt (1995) is the actualization or realization or production process of designed products. Garratt further asserted that, man's likelihood of success in technological advancement that could help him control his environment depend largely on his ability to conceive and translate creative ideas into reality that are functional and user friendly. While, evaluation of a product is defined by Jaries (1982), Joseph and Charles (1989), Garratt (1995) and Ogunlegel (2009) as the operational testing of a new product, against some parameters, to determine whether the product would carry the function (s) for which it was designed.

Agricultural activities are some of the numerous ways man has adopted to control the healthy Vegetative growth and high yield of crops in his environment. Seed application and feeding of crops with required fertilizer are necessary activities that farmers must carry out on the farmland. In other words, maintaining the farmland so that it could trigger healthy vegetative growth and enhance high crop yield are prime objectives of the farmers. Adequate seed broadcasting and feeding of plants through application of appropriate fertilizer are means of achieving these objectives (Love groove, 1978). It is common knowledge that when some plants grow densely as a result of broadcasting of the seeds, it discourages the emergence of weeds. However, this all important and necessary task of seed and fertilizer broadcasting has to be done carefully, accurately and uniformly to achieve desired results.

Historically, man has been using his hand to broadcast seed and fertilizer where and when necessary. This traditional method of seed and fertilizer application is associated with health hazard due to improper washing away of traces of fertilizer off the hands, before eating, after broadcasting the fertilizer. The unwashed fertilizer could be ingested, together with food, and could become cause of health problems in the farmers' system. Another disadvantage of the hand broadcasting is the unevenness in distribution of the seed and fertilizer. The implications of the uneven fertilizer application when using the traditional method are two-fold. First, too much fertilizer at a point may harm the crop; and Secondly, too little feeding may not enhance the desired vegetative growth and maximum yield. Perhaps these problems informed the invention of physical devices for fertilizer broadcasting. 
Today, there are, in the market, various designs of physical fertilizer broadcasting devices such as the tractor driven and the manually push behind types. Lovegrove (1976) reported that tractor mounted fertilizer broadcasters are available. However, the high purchasing cost and high energy requirements of the tractor mounted broadcasters make them 'agricultural technologies for rich farmers' only. Furthermore, the weight of the tractor and the fertilizer distribution device attached to it are too heavy for some soils, especially during the wet seasons, as it causes damage to the soil and many stands of the crop. In the same vein, Sonia (2011) gave a report on a 'manually pushed behind fertilizer broadcaster' which he designed and constructed. The device broadcast or drops the fertilizer as it is moved on the ground, with hand, by the famer. Although this effort reported by Sonia is commendable, however, it has the following short comings. First, it is costly, because its purchasing cost is twenty four thousand three hundred naira ( $\$ 24,300.00$ ) per one; Secondly, when the land is soft and muddy, pushing the device poses a lot of difficulty. Besides, the combined weight of the device and the fertilizer increases difficulty in pushing it on the farmland. These and other short comings observed on the 'traditional'; 'tractor mounted type and the manually pushed behind' methods of applying seed and fertilizer, are current human challenges in agricultural practices. The small scale or peasant farmers suffer social and economic disadvantages as a result of inability to acquire the appropriate seed and fertilizer broadcasting technology.

In the light of the above scenario and since majority of farmers in Nigeria and some other countries of the world are small scale peasant farmers, it is expedient for an appropriate and potable seed and fertilizer broadcasting device to be produced, whose features will eliminate all the short comings observed on the existing methods of seed and fertilizer broadcasting. Further, the small scale farmer will continue to operate at subsistence farming level if the device in view is not provided. Another disturbing situation in which the peasant farmers would be is that, they would not be able to contribute optimally towards economic growth of the society, and so, the objective (s) of the 'Green alternatives' in Nigeria and other parts of the world would not be achieved. In essence, this new agricultural technology being proposed will ensure high productivity of the peasant farmers and positively change their economic status towards national economic development. Its attractive features will include user friendliness, efficiency in function, not heavy to carry, low energy requirement and low purchasing cost. In other words the new product will embody the four qualities of an appropriate technology which are smallness, simplicity, capital saving and free from hazards. Furthermore, mass production of the new product will open employment opportunities for graduates that read mechanical engineering (production option), electrical engineering, Agricultural engineering and marketing. By extension, pressure on government, to create employment opportunities will be eased up.

The above introduction to the background, the problem or challenges being experienced by farmers and the value claim of this current research informed the objectives, the research questions that guided the preliminary investigation; methods and materials and other considerations in this paper.

\subsection{Objectives of the Study}

The following objectives served as guides to this study;

1. The short term goals are, to determine the short comings or problems on the existing designs of seed and fertilizer broadcasting devices that make them in appropriate for present day peasant farmers.

2. The long term goal is, to design, construct and evaluate prototype of a new dual operation seed and fertilizer broadcasting device that is appropriate for teaming population of peasant farmers that grow rice and wheat crops everywhere in the world and whose features will eliminate all the short comings observed on the existing methods of seed and fertilizer broadcasting.

\subsection{Research Questions}

In line with the purposes of the study, answers to the following research questions were sought especially during the preliminary investigation;

1. What is the problem that made the existing method of seed and fertilizer broadcasting inappropriate for today's peasant farmers?

2. What are the desirable features that should be seen on an appropriate seed and fertilizer broadcasting devices for peasant farmers?

\subsection{Materials and Methods}

A laboratory experimental research design was adopted for this study. This research design was chosen because a prototype of the design was constructed. The study area was Adamawa and Gombe States of Nigeria, where agricultural activities are thriving. Preliminary investigation was carried out to reliably and objectively establish the need for the device. Farmers and agricultural extension workers were used as respondents. Open ended and semi structured survey questionnaire were used to collect needed data from the subjects. The researchers generated the questionnaire items that elicited responses towards answering the research questions. The subjects were thirty (30) people randomly selected fifteen from each of the two states in the study area, to whom the questionnaire was 
given. One hundred (100) \% return rate was recorded, perhaps because the researchers directly administered and retrieved the completed questionnaire. The preliminary investigation revealed the following; one, most farmers in the study area are not yet aware of the existence of the push behind fertilizer broadcasting device. Two, where the device were found, the users complained of difficulty in pushing it when the ground is soft and that the costs of acquiring the push behind and the tractor mounted broadcasting devices are too high. These complaints points to the need for fertilizer broadcasting device that is cheap and whose features eliminates the short comings observed on the existing devices.

Having established the need for the device in question, a computer aided technical illustration of the new user friendly broadcasting device was made from the initial freehand and refined sketches. See figures 1a-e for the technical illustration and pictures of the competed broadcaster. The design was based on the design criteria, specification and design calculation of the strengths of the components of the device. Finally, materials for the construction were subsequently selected based on the design calculations.

\subsection{Design Criteria}

According to Hall (1998) and Mele (2006), the question of workability, durability, efficiency and cost effectiveness are vital criteria in design. Therefore, the following design criteria were considered when designing and selecting materials for constructing the device in this study.

1. Functionality: This was considered so that the new device- fertilizer broadcaster- would function according to the intended use.

2. Durability: This was factored in the designing and selection of materials so that the device would last long and not fail in service.

3. Efficiency and Cost Effectiveness: This was born in mind so that the device would function with maximum reliability and thus become worthy of the cost of purchasing.

\subsection{Design Specification}

If a product does not have desirable features, it will not meet the need of end users (Steve, 2000). One of the research questions that guided the preliminary investigation sought information on desirable features that should be seen on an appropriate fertilizer broadcasting device. The knowledge gathered informed the following specified desirable features.

i. Portability:- That the device shall be easy to convey to the farm land and be easy to be carried on the chest in a comfortable strapped position when in use by anybody

ii. Assembling: That the device shall be easy to assemble and dismantle by even the local farmers when need arises.

iii. $\quad$ Operation:- That the device shall be easy to operate by even the local farmers anywhere anytime.

iv. Purchasing cost:- That the purchasing cost shall be affordable, it shall not exceed N 10,000.00

v. Availability:- That the device and its spare parts shall be made available because locally available raw materials shall be used for making the device

vi. Maintenance:- The worn out parts can be replaced easily because of the ease of dismantling and assembling of the parts .

\subsection{Design Calculations}

According Irin and Joseph (1976); Charles (1989), Mele (2006) and Bulama and Mele (2009), fundamental law of forces that should be applied on components are assumed to be either concentrated or distributed. In the case of the components of this design, there is a flywheel that has vertical straight gear teeth cut on both sides of the periphery. The flywheel is cylindrical and has a slot that keys into a horizontal spline on the torque handle. When in use, the torque handle is loaded with concentrated axial load of the flywheel. The intensity of the concentrated load from the flywheel could be made constant or varied. The load from the flywheel can be varied because human energy, through the hand or electrical energy, from a small motor, will be applied eccentrically on the torque handle which will in turn, provide a circular motion on the flywheel. The vertical straight gears cut at the periphery of the flywheel meshes with the teeth of the small pinion gears, one on each of the sides of the flywheel. One of the small pinion gears is connected to the end of the vertical shaft, whose upper end is connected to the distributor disc. Principal performance parameters that were determined through the design calculation are strength, stiffness and diameters of the torque handle and the vertical shaft that is connected to the distributor disc.

According to Joseph and Charles, cited in Apagu, Mele, Dubulo and Angulu (2010), some of the values required for the design calculation may be selected or assumed by the designer to suit the load to be applied and the condition under which the parts or components are to operate. Therefore, factor of safety of two (2) was selected as safety factor during both production and service condition of the product in this study. The rationale is, if the safety factor is below two (2) the component parts will be weak and too light in weight, which could break in service. On the other hand, if the safety factor is above two (2), the components will be too big and overall weight 
of the components will be unnecessarily too much. The situation can best be described as "over design". Another value that was selected is $10 \mathrm{~kg}$ as the overall weight of the broadcaster, which includes the weight of the hopper and fertilizer that will be loaded inside the hopper. This is so that the overall weight of the product will not be uncomfortable for the farmer when he/she hangs it on the chest while in use. Torsion equation was used to determine the diameter of the shafts. The result of the design calculation shows that, the diameter of the vertical shafts is $5 \mathrm{~mm}$ and its length is $75 \mathrm{~mm}$ to which the broadcasting blades will be fixed, while, the diameter of the torque handle, for turning the flywheel is $5 \mathrm{~mm}$ and its length is $100 \mathrm{~mm}$. The efficiency of the electric motor, of 0.5 horse power capacity is $89.5 \%$. Table 1 shows the summary of the materials and dimensions based on design calculations.

Table 1: Summary of materials and their dimensions based on design calculation of Lengths, diameter, rating and factor of safety of the individual components

\begin{tabular}{|l|l|l|l|l|l|l|l|l|l|}
\hline NS & Components & Length & Material & Diameter & Thickness & Width & Efficiency & $\begin{array}{l}\text { Capacity } \\
\text { (rating) }\end{array}$ & $\begin{array}{l}\text { Factor } \\
\text { of safety }\end{array}$ \\
\hline 1. & Blade & $100 \mathrm{~mm}$ & Mild steel & $\ldots \ldots \ldots .$. & $0.8 \mathrm{~mm}$ & $50 \mathrm{~mm}$ & $\ldots \ldots \ldots \ldots$ & $\ldots \ldots \ldots \ldots$ & 2 \\
\hline 2. & Housing & $200 \mathrm{~mm}$ & Plastic & $\ldots \ldots \ldots \ldots$ & $0.8 \mathrm{~mm}$ & $65 \mathrm{~mm}$ & $\ldots \ldots \ldots \ldots$ & $\ldots \ldots \ldots \ldots$ & 2 \\
\hline 3. & Hopper & $300 \mathrm{~mm}$ & Plastic & $\ldots \ldots \ldots$ & $1 \mathrm{~mm}$ & $100 \mathrm{~mm}$ & $\ldots \ldots \ldots \ldots$ & $\ldots \ldots \ldots$ & 2 \\
\hline 4. & Torque handle & $100 \mathrm{~mm}$ & & $5 \mathrm{~mm}$ & & & $\ldots \ldots \ldots \ldots$ & $\ldots \ldots \ldots$ & 2 \\
\hline 5. & Electric motor & & & & & & $89.5 \%$ & $0.5 \mathrm{H} . \mathrm{P}$ & \\
\hline 6. & Vertical shaft & $75 \mathrm{~mm}$ & & $5 \mathrm{~mm}$ & & & & & 2 \\
\hline
\end{tabular}

\subsection{Material Selection for the Study}

Appropriate material for component parts of any product is key to ensuring efficiency and reliability (Nash, 1980; Kenneth, 1983; \& Mele, 2006). Based on the design calculations, semi-finished mild steel, of different shapes and sizes, flat and round, were selected, to which value was added in making some of the components, Also, some finished products, e.g., plastic rack and pinion gears, the type used in existing manual flour blender, were selected and fixed, as they are, in appropriate positions. Specifically, the following were the finished and semi-finished materials selected and used for constructing the prototype of the fertilizer broadcasting device.

i. Mild steel (semi-finished) $5 \mathrm{~mm}$ thick. Used for making the torque handle and the vertical shaft unprotected.

ii. Mild steel (semi-finished): Used for making spinning blade.

iii. The rack and pinion (finished products): The type in existing manual flour blender. These were used as they are, as flywheel and gear, for driving the broadcasting blades.

iv. 6 volts D.C. electric motor (finished products): the type in small rechargeable table fan. The 6 volts $4.5 \mathrm{amp}$ rechargeable battery was used to power the electric motor which in turn powers the flywheel torque handle.

v. Plastic: used for making the housing for the spinning blade and hopper for the seed and fertilizer.

The list of materials items i-iv above were selected based on their quality, strength, affordability and availability in the area where the study was carried out in Adamawa and Gombe states of Nigeria. The materials are available in the two states where the study was carried and are also available in almost every urban and rural area market all over the world. This implies that an entrepreneur may be able to produce this product without having to go far for the raw materials, so that the production cost will be lower, to the advantage of prospective consumers.

\subsection{Materials Specifications and Cost Analysis}

Table 2 shows the components specification of the materials, quantity required, unit cost and total cost of the materials needed to construct each component.

Table 2: materials specifications and cost Analysis

\begin{tabular}{|c|c|c|c|c|c|}
\hline $\mathrm{S} / \mathrm{N}$ & Name of component & Specification & Quantity & Unit Cost & Total Cost \\
\hline 1. & Spinning Housing & G22 mildsteel & 2 & 100.00 & 200.00 \\
\hline 2. & Blade Housing & & 1 & 150.00 & 150.00 \\
\hline 3. & Hopper & Plastic bucket & 1 & 250.00 & 250.00 \\
\hline 4. & Torque handle & Milderod & 1 & 50.00 & 50.00 \\
\hline 5. & Electric motor & 6 volts $4.5 \mathrm{~A}$ & 1 & 1500.00 & 1500.00 \\
\hline 6. & Battery & 6volts & 1 & 2,500 & 2,500 \\
\hline 7. & Vertical shaft & Mildesteel & 1 & 30.00 & 30.00 \\
\hline 8. & Flywheel & Plastic Thick & 1 & 100.00 & 100.00 \\
\hline 9. & Pinion gear & Plastic $8 \mathrm{~mm}$ & 1 & 50.00 & 50.00 \\
\hline 10. & Grant total & & & & $\$ 4830.00$ \\
\hline
\end{tabular}




\subsection{Production of Prototype}

Development, bending, cutting, filing, welding and riveting were the construction techniques used in the production of the components. Detailed working and assembling drawings of each of the component parts were made with computer. The detailed working drawings guided in the accurate production of the components within production tolerance; while the assembling or exploded drawing aided the researchers in assembling the separate components into complete functional unit. However, in this report, to protect intellectual property of this design, only a diagrammatic flow chart that show the relationship between component parts is presented in figure 2 .

\subsection{Total Cost of Production (TCP)}

The TCP is the sum of material cost, direct labour cost and overhead cost. Under normal workshop condition, a total of five (5) hours was directly spent on procurement, production, assembling and painting of the device. 480.00 was assumed to be the cost of semi skill labour per hour. Therefore, the total cost of the labour for the production is $\$ 480.00 \times 5=\$ 2400.00$ while $20 \%$ of the labour cost was assumed to be the cost of overhead $(\mathrm{OH})$. So, $\mathrm{OH}$ cost is $20 \div 100 \times 2400.00=\$ 480.00$. Hence, the TCP was determined as follows: Material cost + labour cost + overhead cost. Thus TCP $=4830.00+2400.00+480=\$ 7710.00$. Assuming that the maximum total cost of advertising, transporting the product to selling point and expected profit from the products that will accrue to the seller is $\$ 1000.00$, it means the maximum purchasing cost is $N 4300.00+\$ 1000=\$ 8710.00$. This is one third of the purchasing cost of the existing broadcasting device. Considering the durability of the product about five (5) years and the efficiency of the product in broadcasting seeds and fertilizer, it is indeed a product which every farmer, rich or poor will want and can afford to buy.

\subsection{Operational Test and Discussion of Results}

After constructing the fertilizer broadcasting device, it was considered a provisional solution to the research problem. Therefore, it became necessary for it to be subjected to certain test parameters to ascertain whether it will perform the function for which it was designed. The following are the test parameters to which the device was subjected to; test for functionality; test for energy requirement; test for maintenance; test for cost effectiveness and production process test.

The test for functionality is a test of performance in relation to the original design specification and the statement of the problem which is also called the design brief. This was meant to determine whether the prototype can actually be used to broadcast seed and granulated fertilizer. To do this, granulated fertilizer and rice seeds were loaded inside the hopper one after the other. Since the device has dual operating systems-electrically and manuallythe manual operating system was first tried. The manual torque handle was rotated slowly at first and then a little faster later. The flywheel, the vertical member and the broadcasting blades all turned together smoothly. As the fertilizer from the hopper was falling onto the spinning blades, the blades threw them away. As the user moved forward, the broadcasted fertilizer was seen to be uniformly distributed and reasonably dense on the ground. The denseness of the fertilizer on the ground depended on the walking speed of the user. The slower the walking speed the denser the fertilizer and vice-visa. For best result, the walking speed should neither be too fast nor too slow. The same result was obtained when trial broadcasting of the rice seed was made.

The electrical operating system exhibited the same behaviour when it was tried. The switch that connects the output voltage of the battery to the 0.5 horse power electric motor was switched on. All the moveable components of the system moved simultaneously and smoothly. A variable resistor knob was used to reduce or increase the speed of the moveable parts. The fertilizer was uniformly broadcasted and was reasonably dense. This clearly meant that the prototype of the fertilizer and seed broadcaster carried out the function for which it was designed smoothly.

The test for energy requirement was meant to determine, especially, how long the small rechargeable battery will last before it become depleted. The device was electrically operated for four hours consecutively for the first day. The second day it was operated again for another four hours at a stretch; after which, the small electric motor began to turn slowly and finally stopped. When it was recharged the device began to work normal again. This meant that the battery can be used for two consecutive days before recharging. This shows that the energy requirement is very low, within acceptable limits of an appropriate technology for both the rich and poor farmers

The maintenance test was meant to determine the ease and safety with which the new product can be serviced. Therefore, trial dismantling and assembling were made. It was observed that each of the components could be removed without difficulty and destroying other components. This is because the component parts were joined together with the help of temporary assembling devices such as nuts and bolts. This advantage definitely contributes to fast and safe servicing of the device.

Production process evaluation was meant to determine whether the production cost, beginning from procurement of the materials to final process of adding value to the materials, could be curtailed and thereby reduce the cost price. Also evaluation was carried in accordance with code of ethics of world of medical association for experiment involving humans - whose link is https://www.wma.net/policies-post/wma-declaration of helsinki. 
The researchers' honest assessment of the construction processes employed is that, they were straight forward and each were carried out with relative ease, and they did not require high skill labour and expensive tools. This meant that appropriate construction techniques and tools were used which contributed to low production cost. This and other tests were carried out on a piece of rice farm land in Modibbo Adama University of Technology, Yola, Nigeria. Financial support was provided by Tertiary Education Trust Fund (TETFUND) through Center for Research Development of the Modibbo Adama University of Technology, Yola (now Modibbo Adama University, Yola). The sponsor was not involved in steady design; in the collection, analysis and interpretation of data; and in the writing of the report.

\subsection{Findings}

The following are the findings from the operational test.

1. The prototype of the seed and fertilizer broadcaster served its designed function efficiently and safely

2. Operating energy requirement is not high

3. Production cost is low, so selling price will be affordable by both the poor and the rich farmers.

4. Maintenance cost is low

5. High skilled labour is not required so, the salary bill will not be too high for entrepreneurs.

6. The production process can be automated so that large quantity of the product can be produced to meet high demand.

7. Local materials can be used to construct the dual operating fertilizer broadcasting device, so that entrepreneurs will not have to go far away looking for raw materials

\subsection{Conclusion}

The outcome of this study-seed and fertilizer broadcaster- has performed, efficiently effectively, and safely, the function for which it was designed and for the fact that mass production of the new fertilizer broadcasting device will bring allot of economic benefits to farmers, entrepreneurs, employment seekers and government, the researchers therefore conclude that the venture is successful. However, since solution to a practical problem today may become obsolete tomorrow, these current researchers recommend that future designers should consider modifying this product to meet future need(s).

Figure. 1: Technical illustration and pictorial views of fertilizer and seed broadcaster
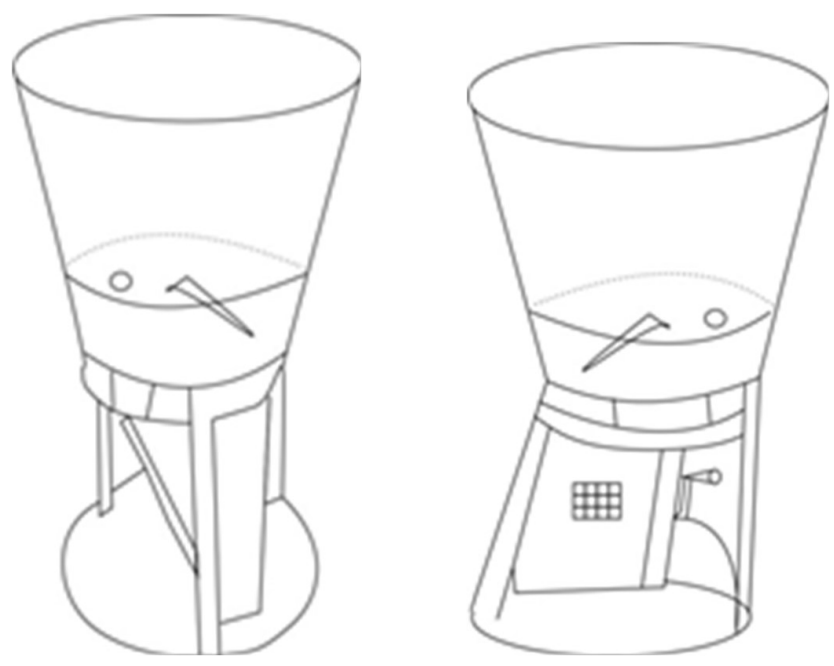

Fig. 1a: Side technical illustration
Fig. 1b: Front technical illustration

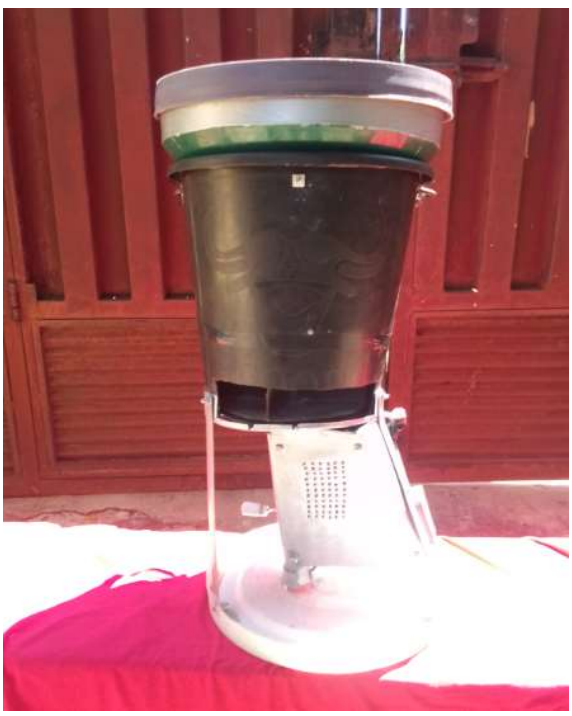

Fig.1c: Complete pictorial view 


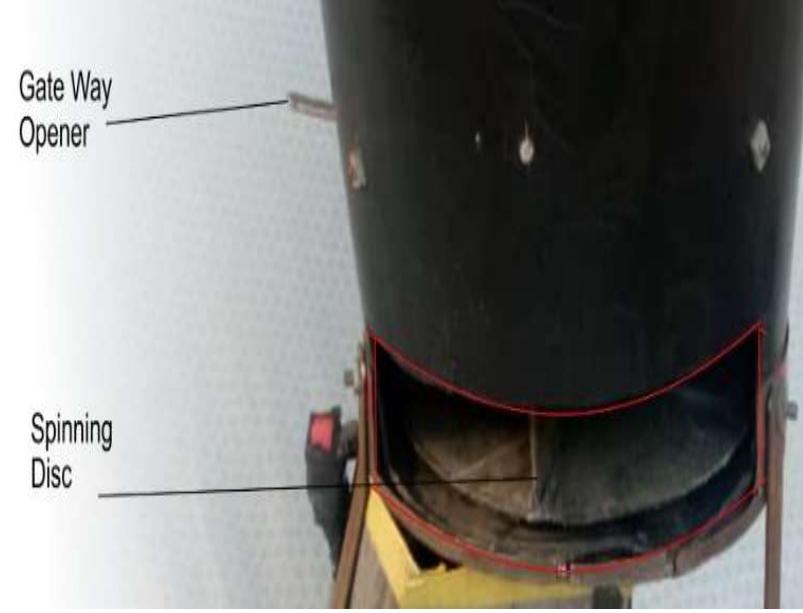

Fig. 1d: part of pictorial view showing the spinning disc

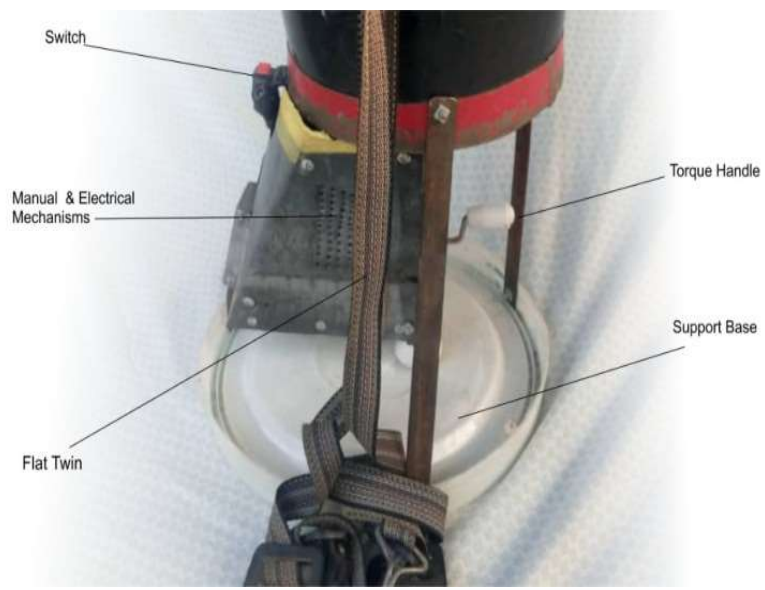

Fig.1e: part of pictorial view showing the switch, the mechanism housing and the base

Hopper that hoses the heed or fertilizer

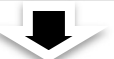

Spinning disc that throws out the speed or

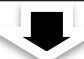

Mechanism (manual or electrical) that turns the spinning disc

\section{Base that support the device when loading and when not in use}

Fig. 2: Schematic diagram

\section{REFERENCES}

Apagu, V.V.; Mele, E.F.; Dubulo, Y. \& Angulu, H. (2010). Design, construction and Testing of Wood Mortising Machine for Rural Wood Workers. Journal of Technology and Educational Research (JOTER). Volume (3) Number 1 .

Bulama, K. H. \& Mele, E. F. (2009). Design and Production of Portable Multi- Function Furniture for Nomadic Education Teachers. A Journal of Scientific and Technological Research.2 (1) 84-89. Federal University of 
Technology Yola, Nigeria Lovegrove, H.T. (1976). Crop Production Equipment. Hutchiuson co-publishers Ltd.3fitzroy Square, London W.

Garratt, J. (1995). Design and Technology. United Kingdom, Cambridge University Press.

Hall, H.L. (1998). Machine Design. Schhuams Outhrie Serio

Irin, H. (1976). Engineering Mechanic, Statistics and Dyuamics. U.S.A. prentice Hall

James, G. (1995). Design and Technology. Cambridge University Press

James, H. E. (1982). Drafting Technology. Addison Publishing Company Lmc. Philipine

Joseph, E.S. \& Charles, R.M. (1989). Mechanical Engineering Design. Singapore.MCgraw Hill lmc.

Kenneth, G.B. (1983). Engineering Materials, Properties and Selection. Virginia, Reston Publishing Company Inc. Mele, E. F. (2006). Design and construction of Convertible Furniture for Nomadic Education Teachers. M. Tech Thesis, Federal University of Technology Yola, Nigeria.

Nash, A. W. (1980). Strength of Materials. Macmillam Publisher LTD. London

Ogunlegel, A. O. \& Fasu, M. B. (2009). Design, Construction and Operation Testing of Rotating Boom Rainfall Simulator, Jounal of FUTAJEET, 4, (2)- 138-142.

Schumacher, E. F.(nd). Appropriate Technology. Community Development Resourses. U.S. A. http/www.villaqueearth.org/pages/AtLibrary/index.htm. Accessedon 11/15/2004.

Steve, H. (2000) Embedded System Design. New Delhi, Publishers Butter worth, Heinemann and Newness. 